\title{
Which are the highest peaks in the US Arctic? Fodar settles the debate
}

\author{
Matt Nolan $^{1}$ and Kit DesLauriers ${ }^{2}$ \\ ${ }^{1}$ Institute of Northern Engineering, University of Alaska, Fairbanks, Fairbanks, AK, USA \\ ${ }^{2}$ The North Face, Teton Village, Wyoming, USA \\ Correspondence to: Matt Nolan(matt2013@drmattnolan.org)
}

Received: 19 November 2015 - Published in The Cryosphere Discuss.: 16 December 2015

Revised: 15 April 2016 - Accepted: 19 May 2016 - Published: 23 June 2016

\begin{abstract}
Though an outstanding achievement for their time, the United States Geological Survey (USGS) topographic maps of the eastern Alaskan Arctic nonetheless contain significant errors, and in this paper we address one of them. Specifically, USGS maps of different scale made in the late 1950s alternate between Mt. Chamberlin and Mt. Isto as the tallest peak in the US Arctic. Given that many of the peaks here are close in height and covered with glaciers, recent climate change may also have changed their height and their order. We resolved these questions using fodar, a new airborne photogrammetric technique that utilizes structurefrom-motion (SfM) software and requires no ground control, and validated it using GPS measurements on the peaks as well as airborne lidar. Here we show that Mt. Chamberlin is currently the third tallest peak and that the order and elevations of the five tallest mountains in the US Arctic are Mt. Isto (2735.6 m), Mt. Hubley (2717.6 m), Mt. Chamberlin $(2712.3 \mathrm{~m})$, Mt. Michelson $(2698.1 \mathrm{~m})$, and an unnamed peak $(2694.9 \mathrm{~m})$; these heights are relative to the NAVD88 GEOID12A vertical datum. We find that it is indeed plausible that this ranking has changed over time and may continue to change as summit glaciers continue to shrink, though Mt. Isto will remain the highest under current climate trends. Mt. Isto is also over $100 \mathrm{~m}$ taller than the highest peak in Arctic Canada, making it the highest peak in the North American Arctic. Fodar elevations compared to within a few centimeters of our ground-based GPS measurements of the peaks made a few days later and our complete validation assessment indicates a measurement uncertainty of better than $\pm 20 \mathrm{~cm}$ (95\% RMSE). By analyzing time series of fodar maps, we were able to detect topographic change on the centimeter level on these steep slopes, indicating that fodar can
\end{abstract}

be used to measure mountain snow packs for water resource availability or avalanche danger, glacier volume change, and slope subsidence, as well as many other applications of benefit to society. Compared to lidar, the current state-of-the-art airborne topographic mapping, we found this SfM technique as accurate, more useful scientifically, and significantly less expensive, suggesting that fodar is a disruptive innovation that will enjoy widespread usage in the future.

\section{Introduction}

Here we seek to answer the overarching question: "how well does modern airborne photogrammetry measure the topography of steep terrain?" We chose to settle the question of the height and order of the tallest mountains in the US Arctic both for its intrinsic value and because these rugged peaks are located in a highly glacierized region in northeastern Alaska (Fig. 1) where we have ongoing glacier research with suitable validation data (Nolan et al., 2011; Weller et al., 2007). The topographic discrepancies in question are shown in Table 1. Here United Sates Geological Survey (USGS) maps indicate Mt. Isto as either being 8975 or $9050 \mathrm{ft}$, depending on map scale, while Mt. Chamberlin is listed as $9020 \mathrm{ft}$ on both (USGS map elevations are reported in feet; see Table 1 for metric conversions). Further, the elevations of Mt. Michelson and an unnamed peak in the Okpilak River valley (which we herein refer to unofficially as Mt. Okpilak) are within a few meters difference, well within the half-contour accuracy specification $(50 \mathrm{ft}$ or $15 \mathrm{~m}$ ) of the maps. Accurate peak elevations are intrinsically interesting to many segments of the public and academia, as well as serving a practical function 
Table 1. Elevations of the five tallest peaks in the US Arctic. USGS peak elevations in feet are taken directly from labels on the printed map sheets except for Mt. Okpilak at 1:63360, which was interpolated from the contours surrounding the peak; Mt. Okpilak is our unofficial name for that unnamed peak. Fodar data were processed in WGS84 for comparison with ground control; as described in the text, we selected one of these measurements (bold) for the final value, which was converted to NAD83 using GEOID12A and presented in column 6, with its geographic coordinate shown in column 7.

\begin{tabular}{|c|c|c|c|c|c|c|}
\hline & $\begin{array}{c}\text { USGS } \\
1: 63360 \\
\text { (NGVD29) }\end{array}$ & $\begin{array}{c}\text { USGS } \\
1: 250000 \\
(\text { NGVD29) }\end{array}$ & $\begin{array}{c}2011 \text { Lidar } \\
\text { (WGS84) }\end{array}$ & $\begin{array}{l}\text { Fodar } \\
\text { (WGS84) }\end{array}$ & $\begin{array}{c}\text { Fodar } \\
\text { (NAVD88 } \\
\text { Geoid 12A) }\end{array}$ & $\begin{array}{l}\text { Latitude, } \\
\text { longitude }\end{array}$ \\
\hline Mt. Isto & $\begin{array}{l}2735.6 \mathrm{~m} \\
\left(8975^{\prime}\right)\end{array}$ & $\begin{array}{c}2758.4 \mathrm{~m} \\
\left(9050^{\prime}\right)\end{array}$ & $2739.63 \mathrm{~m}$ & $\begin{array}{l}2739.59 \text { m (24 March 2014) } \\
\text { 2739.40 m (22 April 2014) } \\
2738.75 \text { m (6 July 2015) }\end{array}$ & $\begin{array}{l}\mathbf{2 7 3 5 . 6} \mathbf{~ m} \\
\left(8975.1^{\prime}\right)\end{array}$ & $\begin{array}{l}69.202506^{\circ} \mathrm{N} \\
143.800941^{\circ} \mathrm{W}\end{array}$ \\
\hline Mt. Hubley & $\begin{array}{l}2717.3 \mathrm{~m} \\
\left(8915^{\prime}\right)\end{array}$ & $\begin{array}{l}2717.3 \mathrm{~m} \\
\left(8915^{\prime}\right)\end{array}$ & $2720.64 \mathrm{~m}$ & $\begin{array}{l}\mathbf{2 7 2 0 . 9 7} \text { m (13 June 2014) } \\
2720.55 \text { (6 July 2014) }\end{array}$ & $\begin{array}{l}\mathbf{2 7 1 7 . 6} \mathbf{~ m} \\
\left(8916.0^{\prime}\right)\end{array}$ & $\begin{array}{l}69.276101^{\circ} \mathrm{N} \\
143.799277^{\circ} \mathrm{W}\end{array}$ \\
\hline Mt. Chamberlin & $\begin{array}{c}2749.3 \mathrm{~m} \\
\left(9020^{\prime}\right)\end{array}$ & $\begin{array}{l}2749.3 \mathrm{~m} \\
\left(9020^{\prime}\right)\end{array}$ & $2717.29 \mathrm{~m}$ & $\begin{array}{l}\text { 2716.51 m (24 March 2014) } \\
\text { 2716.59 m (22 April 2014) } \\
2717.56 \text { (23 April 2015) }\end{array}$ & $\begin{array}{l}\mathbf{2 7 1 2 . 3 ~ m} \\
\left(8898.6^{\prime}\right)\end{array}$ & $\begin{array}{l}69.277673^{\circ} \mathrm{N} \\
144.911625^{\circ}\end{array}$ \\
\hline Mt. Michelson & $\begin{array}{l}2699.0 \mathrm{~m} \\
\left(8855^{\prime}\right)\end{array}$ & $\begin{array}{l}2699.0 \mathrm{~m} \\
\left(8855^{\prime}\right)\end{array}$ & $2702.29 \mathrm{~m}$ & $\begin{array}{l}\text { 2701.30 m (30 June 2014) } \\
\text { 2701.69 m (6 July 2015) }\end{array}$ & $\begin{array}{l}\mathbf{2 6 9 8 . 1} \mathbf{~ m} \\
\left(8852.0^{\prime}\right)\end{array}$ & $\begin{array}{l}69.307756^{\circ} \mathrm{N} \\
144.268992^{\circ} \mathrm{W}\end{array}$ \\
\hline Mt. Okpilak & $\begin{array}{c}2697.5 \mathrm{~m} \\
\left(8850^{\prime}\right)\end{array}$ & $\begin{array}{l}2670.0 \mathrm{~m} \\
\left(8760^{\prime}\right)\end{array}$ & $2699.84 \mathrm{~m}$ & $\begin{array}{l}\text { 2699.95 m (23 April 2015) } \\
\mathbf{2 6 9 9 . 8 0 ~ m ~ ( 6 ~ J u l y ~ 2 0 1 5 ) ~}\end{array}$ & $\begin{array}{l}\mathbf{2 6 9 4 . 9} \mathbf{~ m} \\
\left(8841.5^{\prime}\right)\end{array}$ & $\begin{array}{l}69.14572^{\circ} \mathrm{N} \\
144.041046^{\circ} \mathrm{W}\end{array}$ \\
\hline
\end{tabular}

in aviation planning. Our interest in measuring these peaks stems primarily from our studies of the glaciers that descend from them. Located in the pristine Arctic National Wildlife Refuge along with all of these peaks, McCall Glacier has served as the sole benchmark glacier for the entire US Arctic since 1957, such that we extrapolate our local measurements from there to inform us on the impacts of climate change on the broader landscape and its ecology (Nolan et al., 2011). Ideally we wish to avoid such extrapolation by directly measuring volume change for all of the $800+$ Arctic glaciers annually, which is not feasible to do from the ground in this remote, roadless terrain. We have in the past used airborne InSAR and airborne lidar and found them useful but prohibitively expensive for sustainable academic research budgets (Geck et al., 2013). This financial obstacle led us to the development of a new photogrammetric technique. Our study of the tallest peaks in the US Arctic thus serves a dual purpose - both to resolve the discrepancies in existing maps and to use those same data to validate this technique as a means to affordably measure changes to snow and ice on the centimeter scale within steep mountain environments.

We have given this photogrammetric technique its own name, fodar, because we believe it is substantially different from existing techniques and represents a new standard in performance and cost. Note that fodar is a portmanteau of "foto" and "lidar" (https://en.wikipedia.org/wiki/Lidar); it is not an acronym nor is it capitalized. Our design goal was to affordably map the topography of large, remote areas at high accuracy using manned aircraft and requiring no ground control. In previous work, we demonstrated our success by cre-

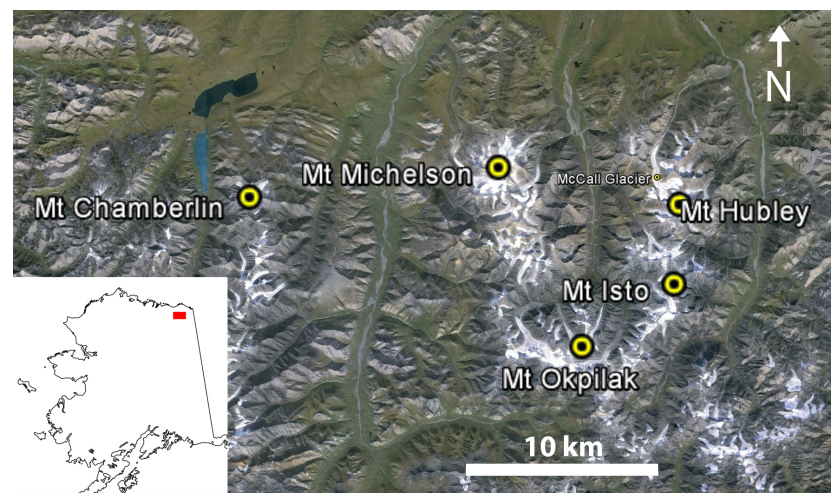

Figure 1. The five tallest peaks in the US Arctic are located within about $40 \mathrm{~km}$ of each other in northeastern Alaska, within the Arctic National Wildlife Refuge.

ating maps with 10-20 cm ground sample distances (GSDs) over tens of square kilometers and validating that they had a directly georeferenced accuracy and map precision (repeatability) better than \pm 30 and $\pm 8 \mathrm{~cm}$, respectively, at $95 \%$ rootmean-square error (RMSE) (Nolan et al., 2015). The method is distinguished from traditional methods of photogrammetry by its use of the structure-from-motion (SfM) algorithm (Koenderink and Van Doom, 1991; Westoby et al., 2012; Nolan et al., 2015), and it is distinguished from other forms of SfM photogrammetry by the fact that no ground control is required to achieve such accuracy and precision. Ground control is not required because the precise timing between the shutter of the camera and survey-grade GPS yields abso- 
lute photo locations with less than $10 \mathrm{~cm}$ error, and this constrains the SfM bundle adjustment sufficiently to meet these specs. Thus if any ground control is utilized, it is only after the map is created, to shift the entire map uniformly by less than $30 \mathrm{~cm}$ some direction. Though SfM photogrammetry is currently exploding in scientific popularity with cameras mounted on inexpensive drones (d'Oleire-Oltmanns et al., 2012; Hugenholtz et al., 2013; Lucieer et al., 2013; Rinaudo et al., 2012; Ryan et al., 2015), directly georeferenced results from these systems generally have accuracies and precisions $10-100 x$ worse than fodar because they lack surveygrade GPS on-board to constrain photo locations as well as fodar. Without precise positioning in the air, substantial photo-identifiable survey-grade ground control needs to be incorporated into the bundle adjustment before the map is created, a time-consuming process similar to traditional photogrammetric methods, in order to improve accuracy and precision. Practically speaking it is unclear as yet whether sufficient ground control can ever be acquired to match fodar specs over the spatial scales we are operating at. Thus fodar could be regarded as survey-grade SfM photogrammetry and considered in much the same way that consumer GPS is distinguished from survey-grade GPS - both are useful, but which tool to use depends on the questions trying to be answered.

In prior work, we have shown that fodar is as accurate as alternative methods but substantially less expensive. By subtracting snow-free digital elevation models (DEMs) from snow-covered ones, we found fodar was suitable for measuring thin $(<30 \mathrm{~cm})$ Arctic snow depths on the watershed scale with accuracies as good as hand probing (Nolan et al., 2015). Studies of coastlines in Alaska independently validated fodar specifications, demonstrating that coastal erosion could be measured by such DEM differencing as accurately as ground measurements but over much larger areas (Gibbs et al., 2015) and that coastal mean high water vectors could be extracted from fodar DEMs with about the same accuracy as manual digitization but much more efficiently (Kinsman et al., 2015). Independent validation using about 100 ground control points (GCPs) by the state of Alaska of DEMs we made of 26 coastal villages revealed that directly georeferenced horizontal accuracy was $<10 \mathrm{~cm}$ in all cases, that the mean directly georeferenced vertical offset was $21 \mathrm{~cm}$, and that vertical precision was $10 \mathrm{~cm}$ at 2 standard deviations (Overbeck et al., 2016); since then we have mapped over $3000 \mathrm{~km}^{2}$ of coast in Alaska for similar purposes (Nolan, unpublished data). In remote locations like these, the field effort to collect ground control can greatly exceed the cost of the airborne survey itself; thus fodar can result in tremendous savings of both cost and time. Fodar specifications also meet or exceed the capabilities of most airborne lidars, the current state-ofthe-art topographic mapping (Deems et al., 2013; Höfle and Rutzinger, 2011), yet fodar hardware costs less than USD 30 000 compared to USD 500000 to USD 1 million for airborne lidar hardware suitable for mapping mountain ranges. As de- scribed in detail in Nolan et al. (2015), the primary underlying reason for the difference in price is due to the software utilization of the SfM algorithm that allows for prosumergrade cameras to be used without the need for an IMU, an on-board computer, or a separate equipment operator.

To address the overarching question of this paper, we mapped each of the five highest peaks photogrammetrically between two and four times in 2014-2015. These repeat measurements let us not only determine the repeatability (precision) of our methods in steep terrain but also detect change of snow and ice surfaces over time. We compared these measurements to survey-grade GPS measurements we made by climbing to the top of Mt. Isto (Fig. 2) and Mt. Chamberlin, as well as to lidar measurements we made of all five peaks between 2008 and 2011. Comparing all measurements also allowed us to examine rates of change of peak elevation, caused by ice and rock loss from their summits.

\section{Methods}

\subsection{Fodar}

We mapped each of the five mountains at least two times in 2014-2015 (Table 1) using our photogrammetric system, flown in a Cessna $170 \mathrm{~B}$ or Piper Lance by the first author. In total we flew 10 airborne missions from Fairbanks, Alaska, to the study area $500 \mathrm{~km}$ away (Fig. 1), though not every flight resulted in data published here due to weather or acquisition issues. Our flight lines were typically flown at between 10000 and $11,000 \mathrm{ft}(3050 \mathrm{~m}-3350 \mathrm{~m})$, resulting in image GSDs ranging from $5 \mathrm{~cm}$ near the summits to about $50 \mathrm{~cm}$ within the valleys. We processed the images into DEMs with postings ranging from 37 to $51 \mathrm{~cm}$. The photogrammetric system and its processing is fully described in Nolan et al. (2015). In short, it utilizes a Nikon D800E, a Nikkor $24 \mathrm{~mm}$ lens, a Trimble 5700 with roof-mounted L1/L2 antenna, and a custom intervalometer that triggers the camera and sends an event pulse to the GPS. GPS processing was done in Novatel's Grafnav software using the PPP method (Gao and Shen, 2002) to create an exterior orientation file that is imported in Agisoft's Photoscan for bundle adjustment and DEM creation. We processed our GPS data from the start time forwards in time and separately from the end time backwards in time, a common technique for assessing error. Comparison of forward/reverse solutions and other internal software metrics indicates that the positional accuracy of the camera was $10 \mathrm{~cm}$ or better typically, except when excursions occurred due to loss of satellite numbers or lock, usually caused by banking too steeply. The subsequent bundle adjustment within Photoscan confirmed this accuracy with mean shifts in photo locations of less than $10 \mathrm{~cm}$. GPS solutions and the subsequent DEMs were processed relative to the WGS84 ellipsoid to facilitate comparison with lidar data, with peak eleva- 


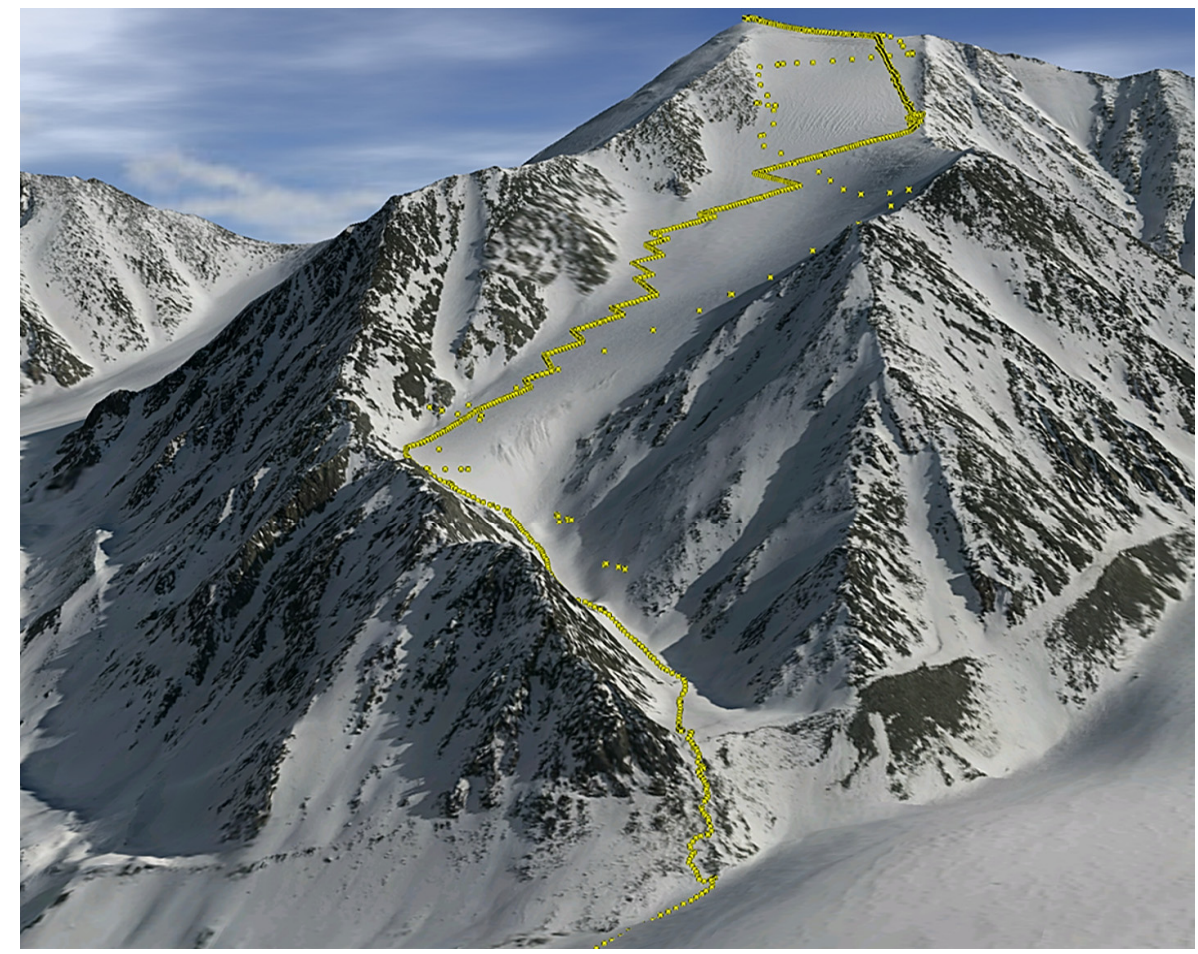

Figure 2. Mt. Isto, currently the tallest peak in the US Arctic, shown as a 3-D visualization of our fodar data. Yellow dots indicate the position of some of the ground control points collected (yellow) used for validation, spanning $\sim 1000 \mathrm{~m}$. Closely spaced points are on the climb up; widely spaced points are on the ski down.

tions converted to NAD83(2011) NAVD88 GEOID12A using NOAA's online tools (http://www.ngs.noaa.gov/cgi-bin/ GEOID_STUFF/geoid12A_prompt1.prl). Fodar creates not only a DEM but also a perfectly co-registered orthoimage; herein we use "map" generically to refer to both products.

\subsection{GPS ground control}

We conducted field campaigns to climb Mt. Isto (27 April 2014) and Mt. Chamberlin (3 May 2014) to directly measure peak elevations, shortly after our primary airborne mapping mission there (22 April 2014), with a climbing team led by the second author. A Trimble 5700 GPS receiver with compact L1/L2 antenna was mounted on a backpack and continuously recorded during the ascents and descents (e.g., Fig. 2). Static occupations near the summits of both peaks ranged from 10 to $20 \mathrm{~min}$, with the antenna either placed on a spike mount or left on the backpack which was dug into the snow for stability; because the peaks themselves were on or near cornices, the summit occupations were made $\sim 5 \mathrm{~m}$ horizontally away from the actual peaks for safety concerns. Novatel's Grafnav software using the PPP method was used for all processing, given that the nearest high-quality CORS site (Snay and Soler, 2008) was over $160 \mathrm{~km}$ away and no local base station was installed due to weight and logistical requirements.
The nominal antenna height on the backpack was $2.14 \mathrm{~m}$; practically it varied from 0 while climbing steep ice to $1 \mathrm{~m}$ while wading through deep snow, and thus it varied between 0 and $2.14 \mathrm{~m}$. Given the extreme antenna motion during climbing, broad sections of this kinematic session failed to process and much of it had errors on the $1 \mathrm{~m}$ level. We therefore filtered these GCPs to those locations where we were mostly walking upright on hard ice, as here we knew the antenna height and the improved antenna stability led to forward/reverse solution separation less than $20 \mathrm{~cm}$; this occurred mostly near the summit ridges. Comparison of forward/reverse solutions indicated that static sessions had an accuracy of about $\pm 10 \mathrm{~cm}$. Note that our fodar validation comparisons were made to these offset measurements and that the peak measurements published here are from the highest point on the maps, not the height of these GCP locations. The same GPS system was used on McCall Glacier, directly beneath Mt. Hubley, prior to our June 2014 airborne measurements of it. The antenna was mounted on a snow machine with a nominal antenna height of $1.08 \mathrm{~m}$ and variations likely less than $\pm 0.15 \mathrm{~m}$. These data were processed the same way and further filtered by distance to provide $5 \mathrm{~m}$ spacing between points and to ensure their solutions were accurate to $<10 \mathrm{~cm}$. 


\subsection{Lidar}

The lidar DEMs were acquired by a commercial vendor using an Optech ALTM Gemini system and delivered to us both as individual-swath point clouds and merged DEMs between 2008 and 2011. Using the swath data, we compared overlapping regions of adjacent swaths to assess system precision using repeatability as a metric. Two DEMs were acquired in 2008: one small DEM of just McCall Glacier had a precision of $16 \mathrm{~cm}$ (95\% RMSE) and a second larger DEM one that covered all of the glaciers in this region (as well as the five peaks) at a precision of over $3 \mathrm{~m}$ due to a variety of quality control and planning issues. Acquisitions of the larger area was thus repeated in 2009 and 2010, but these also suffered from a variety of issues. In 2011, a new map of the entire area had a measured precision of $\pm 50 \mathrm{~cm}$ (95\%) between adjacent swaths, and related swath-edge artifacts could be found within the DEM at this level. We extracted several large blocks of data (all with $n>10^{6}$ ) from both the small (better) 2008 DEM and the large 2011 DEM over ice-free rocks to further assess repeatability and found similar scatter of about $\pm 0.50 \mathrm{~m}(95 \%)$ about the mean. This value was apparently driven by the 2011 data quality, as the point density of the 2008 data was more than 4 times higher than the 2011 data, leading to 1 and $2 \mathrm{~m}$ postings, respectively, and thus spatial biasing of the coarser pixels in rough terrain may be the limiting factor in repeatability here. According to the metadata, the 2011 data were shifted down $0.75 \mathrm{~m}$, based on co-registration with the worse of the two 2008 DEMs that covered a much larger area, which had apparently already been shifted down $0.20 \mathrm{~cm}$ based on some limited ground control on tundra acquired by the vendor. We therefore used GCPs collected by us within a few weeks of the 2011 lidar acquisition using a snow machine transect on McCall Glacier ( $n=1703,1500-2340 \mathrm{~m}$ HAE$)$ as described above and found a mean offset of $0.61 \mathrm{~cm}$ (upward DEM shift) with standard deviation of $0.10 \mathrm{~m}$. Unfortunately the 2011 data were delivered in two non-contiguous blocks and our GCPs come only from the eastern one; however, as described later, comparison of rock areas between the lidar and our SfM maps on both blocks showed that this $0.61 \mathrm{~m}$ shift reduced the mean residual difference to within $\pm 0.10 \mathrm{~m}$, and thus we applied this shift to both lidar blocks.

\section{Accuracy and precision assessments}

We assessed horizontal geolocation accuracy of the fodar DEMs by assessing co-registration offsets between our repeat maps, because none of our GCPs were photoidentifiable. While in principle comparing maps to themselves only assesses precision and not accuracy, our prior work with photo-identifiable GCPs demonstrated that such comparisons yield the same results as GCP comparisons (Gibbs et al., 2015; Kinsman et al., 2015; Nolan et al.,
2015; Overbeck et al., 2016). Using two orthoimages each on Mt. Isto, Mt. Chamberlin, and Mt. Michelson made in 2014, we used standard image-correlation techniques in Matlab to determine there was a sub-pixel $(5-10 \mathrm{~cm})$ horizontal coregistration between them. In other work, we have also mapped the McCall Glacier valley five times from 2013 to 2015 and again found that horizontal coregistration was subpixel (Nolan, unpublished data). Given that our pixels are roughly $25 \mathrm{~cm}$ GSD and our camera positioning accuracy is $10 \mathrm{~cm}$ or better, this subpixel horizontal accuracy makes sense, but given the ambiguities caused by the amount of real change on the surface due to snow, it was not possible to determine a precise value. Thus our assessment of the horizontal geolocation accuracy of our maps is that they are accurate to the subpixel level as we found in previous studies and we therefore applied no horizontal geolocation offsets to these data. We validated this horizontal accuracy visually by creating difference maps of all peaks and found no systematic horizontal alignment issues, though this was difficult to assess visually at the decimeter level because real changes on ground revealed correlations with aspect, largely due to wind direction and solar aspect. Figure $3 \mathrm{a}$ shows an example of this on Mt. Chamberlin. On a broad scale, the southeast face (right) shows strong avalanche dynamics, the southwest face (left) shows melt dynamics, and the northwest face (top) shows glacier motion and wind redistribution. Note that the color scale here is only $\pm 50 \mathrm{~cm}$, so even if these differences were caused by misalignment, that misalignment must be quite small in this steep $\left(>45^{\circ}\right)$ terrain. On the scale of a few hundred meters (e.g., small rock outcrops), dozens of informal transects revealed no systematic offsets, providing further validation.

We assessed vertical geolocational accuracy by comparison with our GCPs. On Mt. Chamberlin, the 24 March and 22 April fodar elevations were -0.18 and $-0.04 \mathrm{~m}$ different, respectively, from the near-summit GPS measurement on 3 May of $2716.38 \mathrm{~m}$ HAE (note that this measurement was taken about $10 \mathrm{~m}$ from the true summit and relative to the WGS84 ellipsoid). Kinematic points near the summit $(n=288,2411-2513 \mathrm{~m}$ HAE $)$ were -0.17 and $+0.08 \mathrm{~m}$ from the March and April map elevations, respectively, with a $\pm 0.10 \mathrm{~m}$ standard deviation. Though the March map has a larger offset, it is not unreasonable to expect $10-20 \mathrm{~cm}$ of change on these snow- and ice-covered locations over the intervening month. Given that these residuals for the 22 April map are within the accuracy of the GPS, we did not apply any shifts to these maps to geolocate them further. On Mt. Isto, we found the 24 March and 22 April maps within -0.06 and $-0.03 \mathrm{~m}$, respectively, of the 27 April near-summit GCP measurement of $2738.88 \mathrm{~m}$ HAE. Kinematic points near the summit ( $n=1247,2735-2736$ m HAE) showed residuals of +0.26 and $-0.05 \mathrm{~m}$ for the March and April maps, respectively, with a $0.27 \mathrm{~m}$ standard deviation. Again given that the April residuals (made 5 days apart) are within their error bounds and March measurements so close, we did not 
(a)

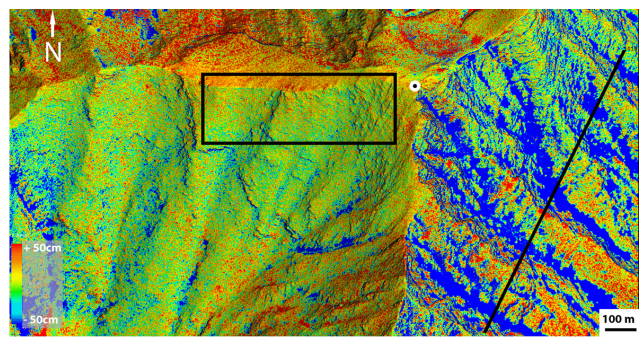

(b)

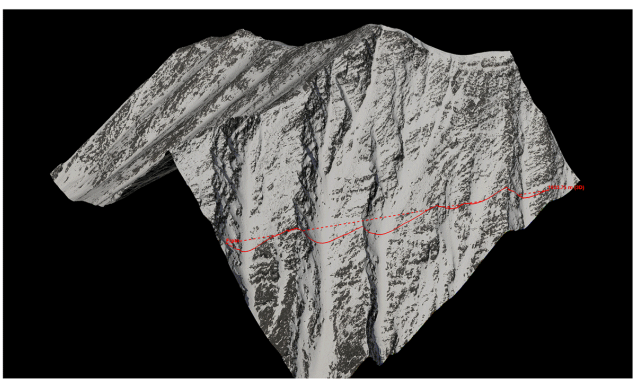

(c)

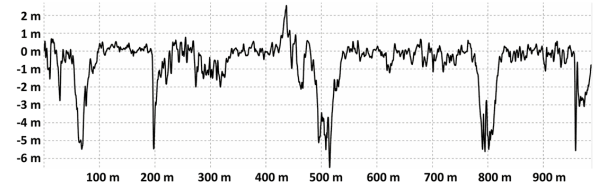

(d)

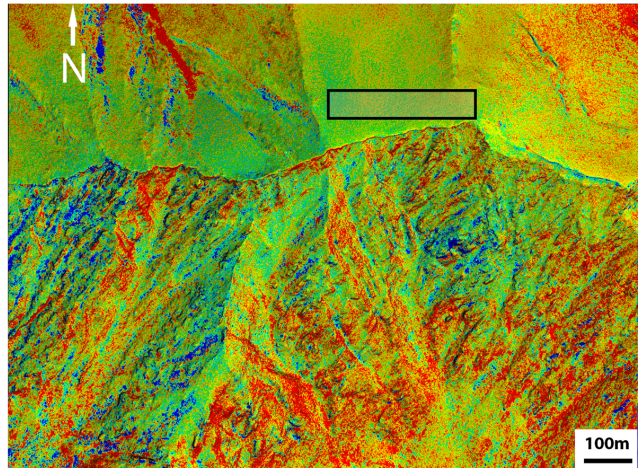

(e)

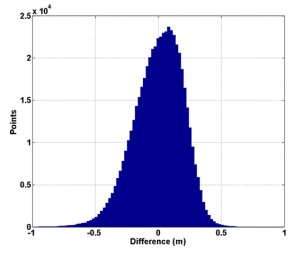

(f)

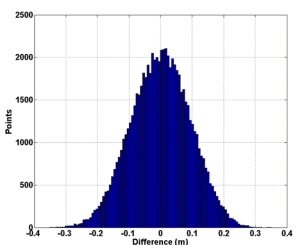

Figure 3. Precision assessments. (a) Difference in elevation between March and April 2014 acquisitions at Mt. Chamberlin, shown as a top view with slight sun shading to highlight underlying topography. Color represents change $(-50$ to $+50 \mathrm{~cm})$. The consistency of color shift between mountain faces is not due to a spatial misalignment of the data but rather to substantial, real changes that are dependent on aspect, as described in the text. Such real changes confound our repeatability estimates which assume no change on the ground. (b) 3-D oblique view of domain in (a), draped with orthoimage from April, indicating the locations of snow-filled gullies on the southeast face. Profile line is shown as both a straight line and terrain hugging line and is about $1000 \mathrm{~m}$ long, crossing five gullies. (c) Profile of elevation difference (that is, data in a), revealing patterns of snow redistribution. Much of the snow that had recently fallen in March avalanched out of the gullies, leaving them up to $6 \mathrm{~m}$ deeper in April. Note that the ridges in between show little to no change, qualitatively indicating the high quality of the data and the technique's suitability for measurement of snow depth in steep terrain. (d) Difference in elevation between March and April 2014 acquisitions at Mt. Isto, with same coloration as (a). Again, there is substantial real change between acquisitions, but less than in (a). Histogram of differences of elevations calculated from boxes in (a) and (e) shown in (d) and (f) respectively over smoother glacier surfaces. Both are roughly gaussian with $95 \%$ of points within \pm 38 and $\pm 20 \mathrm{~cm}$. Inspection of orthoimages here reveals that real changes are still occurring on the glaciers in these smaller domains, but there are no large locations that have less change, so these estimates of precision are conservative as they are confounded by real change. 
apply any geolocation offsets to these maps either. For the Mt. Hubley map, we compared snow machine GCPs from McCall Glacier ( $n=1432,1500-1900 \mathrm{~m}$ HAE) acquired on 28 April 2014 to the SfM map made on 16 June and found a mean offset of $-0.10 \mathrm{~m}$ with a standard deviation of $0.15 \mathrm{~m}$. Given that this is within the noise level of both measurements and an unknown amount of melt occurred (probably less than $10 \mathrm{~cm}$ ), we applied no shift to these data either. That is, we consider the fodar maps to be as accurate as our GCP validation data in all cases, with those measurements having the least temporal influence all within $\pm 10 \mathrm{~cm}$. We have no GCPs for comparison to Mt. Chamberlin or Mt. Okpilak, though informal comparison of some rock areas here to the 2011 lidar showed near perfect vertical agreement.

We assessed precision of the fodar DEMs primarily by comparing repeat maps to each other in areas where real changes to the surface were minimized. In the context of this paper, we consider precision to be analogous with repeatability, and we use this repeatability to determine the measurement uncertainty in our peak measurements. Unfortunately 2014 was an unusually snowy spring and it was impossible to find large blocks of data that were free of change due to snow or ice (e.g., Fig. 3a). Figure $3 b$ and c give a clear example of the real changes on the ground that confound attempts to use large-scale repeatability as a measure of precision with measurements only 1 month apart. Here a fresh snowfall in March has largely avalanched off in the gullies by April, causing the April DEM to be up to $6 \mathrm{~m}$ lower within them, as seen in Fig. 3c. The ridges in between the gullies show little to no change, as validated by the orthoimages, and this profile is typical of many that we extracted here. Figure $3 \mathrm{~d}$ shows Mt. Isto similar to Mt. Chamberlin in Fig. 3a; note that there is somewhat less aspect-dependent difference. In the full domains of Fig. 3a and d, we found $95 \%$ of points were within \pm 140 and $\pm 52 \mathrm{~cm}$, respectively $\left(n>10^{7}\right)$. Within the subdomains indicated by the black rectangles, however, these values dropped to \pm 38 and $\pm 20 \mathrm{~cm}$, respectively $\left(n>10^{6}\right)$, as shown in Fig. 3e and f; carefully choosing yet smaller domains results in yet smaller differences. We believe these values are more representative of our actual precision, though are still erroneously high due to real changes still being captured here (more so on Mt. Chamberlin). We found values of $\pm 20 \mathrm{~cm}$ on the other mountains as well for areas of about this size. This precision is about twice as high as we found previously $(\sim 8 \mathrm{~cm})$ on smooth, low-relief surfaces like runways and frozen lakes (Nolan et al., 2015), and we suspect that the bulk of the difference is due to real change and to spatial biasing caused by averaging of steep terrain into relatively large pixels. The scatter in our GCP comparisons is another measure of precision, and perhaps a better one since there was less intervening real change on the ground. As described previously, in our April comparisons (5-day interval), we found $95 \%$ of points within $\pm 7 \mathrm{~cm}$ combining data for both peaks, similar to the values we found in our prior study.
Thus we believe a conservative reasonable estimate of our precision on mountain peaks to be $\pm 20 \mathrm{~cm}$.

Based on these comparisons, our assessment is that the horizontal and vertical geolocation accuracy of $\pm 10 \mathrm{~cm}$ in steep terrain is better than we found previously in flat to moderate terrain at $\pm 30 \mathrm{~cm}$ (Nolan et al., 2015), and we thus made no corrections to our maps based on ground control. That is, the DEMs we created using only airborne data cannot be improved further using all of the ground control available to us. Given that we found our precision was $\pm 20 \mathrm{~cm}$ and that we found no consistent systematic bias in our accuracy, we conservatively consider this our accuracy level too, noting that our precision values are likely artificially high due to undocumented real changes to the surface and due to spatial biasing. In any case, based on this analysis, we conservatively consider the measurement uncertainty in our peak elevations to be $\pm 20 \mathrm{~cm}$ at $95 \%$ confidence.

\section{Peak elevations}

We determined peak elevations simply by locating the highest pixel for each mountain within its DEM, which all had postings of $51 \mathrm{~cm}$ or smaller. For our final results (Table 1, in bold), we selected the values from those maps that were made closest in time to our GCPs for the tallest three, and because we had no GCPs for the other two we used the 6 July 2015 measurements for both to provide the best comparison by eliminating uncertainties due to any temporal changes. As seen in Table 1, the measured differences in peak elevations $(3-18 \mathrm{~m})$ are all greater than the uncertainty of those measurements $(20 \mathrm{~cm})$, lending strong confidence that they are currently ranked correctly by elevation. Our fodar and GPS measurements confirm that none of the peaks are over $9000 \mathrm{ft}$ $(2743 \mathrm{~m})$ and that Mt. Chamberlin is not the tallest peak in the US Arctic, as indicated by the 1:63360 scale maps, but rather is currently the third tallest peak, as originally indicated by our lidar. Figure 4 presents 3-D synthetic visualizations of several of these peaks using fodar DEMs and orthoimages.

\section{Discussion}

Based on our results, there is no longer doubt regarding the tallest peak in the US Arctic today: Mt. Isto at $2736 \mathrm{~m}$. Given the consistency between our results and the 1:63360 $(8975 \mathrm{ft})$ maps, it seems clear that the $9050 \mathrm{ft}$ measurement indicated on the $1: 250000$ scale map was in error. Note that none of the peaks today are over $9000 \mathrm{ft}$, as indicated on the USGS maps (made over 60 years ago) and still republished today in the FAA's aviation sectional charts. Given that the highest peak in the Canadian Arctic is Barbeau Peak on Ellesmere Island at $2616 \mathrm{~m}$ and that it is unlikely that any potential mapping errors there exceed the $120 \mathrm{~m}$ difference, Mt. Isto is also the highest peak in the North American Arc- 
(a)

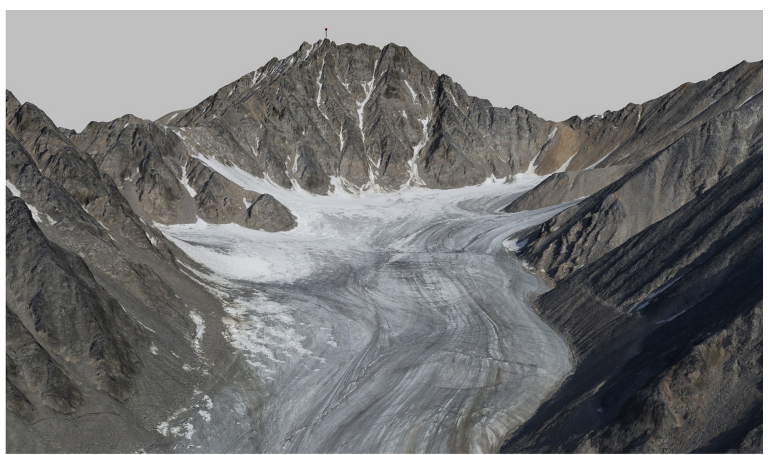

(b)

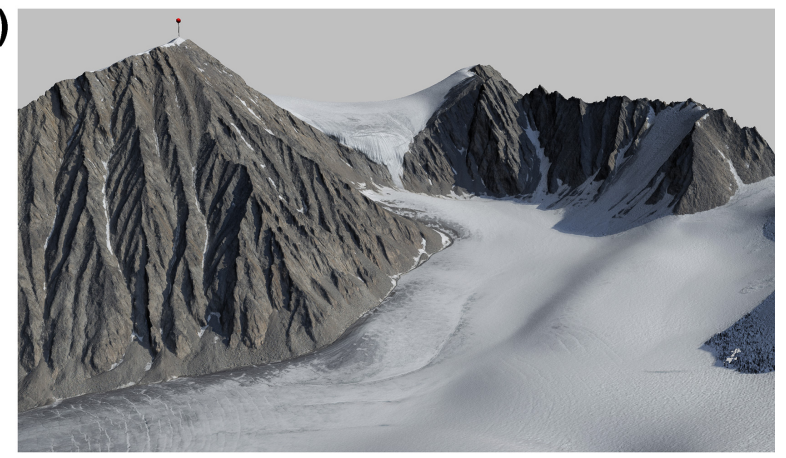

(c)

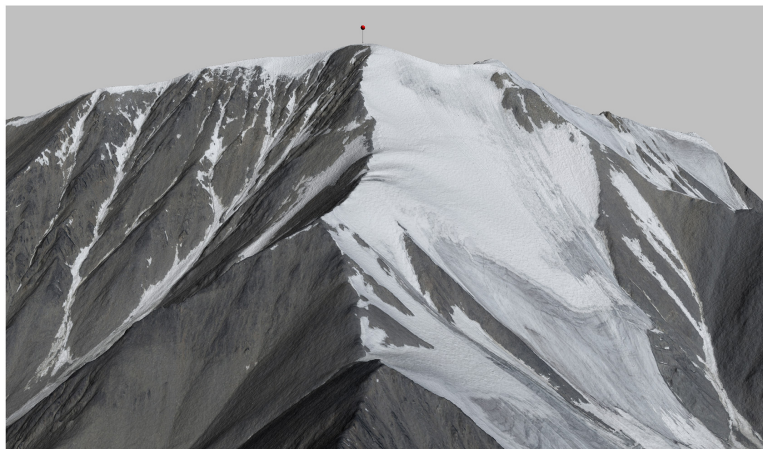

Figure 4. Oblique 3-D visualizations using our fodar data of (a) the south face of Mt. Hubley with Schwanda Glacier in foreground, (b) the south face of Mt. Michelson descending to Esetuk Glacier, and (c) the south and east faces of Mt. Okpilak. Red markers indicate peak location. Note the slight noise seen at the shadow on the right of (b); this was common at the edge of dark, fast-moving shadows. Despite the range of exposure value and contrast, this technique is able to map nearly all terrain, and the orthoimage eliminates guesswork when it comes to distinguishing rock and ice and even ice and snow.

tic and, to our knowledge, the highest Arctic peak outside of Greenland.

Given the survey control available in Arctic Alaska in the late 1950s, it is remarkable how well the USGS elevations compared to our own. As there is no official transformation between the USGS map datum of NGVD29 and the current NAVD88 datum in Alaska, we cannot directly compare these elevations, but likely these transformations would be less than $2 \mathrm{~m}$, based on several benchmark surveys. Note too that the latest official geoid model available from
NOAA, GEOID12A, will soon be replaced by GEOID15B, and our use of the $15 \mathrm{~B}$ model indicates the elevations will uniformly decrease by about $1.4 \mathrm{~m}$. Ignoring these uncertainties, four out of five peaks on the 1:63360 maps are within $1-2 \mathrm{~m}$ of our measurements, well within the published uncertainty of those maps of $15 \mathrm{~m}$, and truly a testament to the quality of the survey teams and photogrammetrists that produced those maps in such challenging circumstances. Unfortunately, given the published uncertainty of $15 \mathrm{~m}$, we cannot rule out that this amazing correspondence in actual peak values was not spurious. However, given that the $33 \mathrm{~m}$ difference at Mt. Chamberlin is more than double the published uncertainty and that the other peaks showed a much closer correspondence with our measurements, it is conceivable that some portion of this difference at Mt. Chamberlin could be due to a real change here over the past 50 years.

Our own results show that elevation change occurs here essentially continually; that is, the scatter in our own measurements is not due solely to measurement error either. For example, on Mt. Okpilak we found that the location of the peak moved more than $15 \mathrm{~m}$ laterally between April and July 2015 even though the elevation changed by only $15 \mathrm{~cm}$, as the peak is located on a broad, flat corniced ridge. Similarly, the $1 \mathrm{~m}$ difference on Mt. Chamberlin between April 2014 and April 2015 was largely real, since nearby rock did not show any such difference with analyses similar to Fig. 3 . Thus the short-term temporal variations in actual peak height are likely as high or higher than the uncertainty in our measurements, and any future measurements should anticipate at least a $\pm 1 \mathrm{~m}$ uncertainty due to recent storms. While such dynamics are noise for this study, our results indicate that our methods are a valuable new tool in the study of snow thickness (e.g., Fig. 3c), wind redistribution (e.g., Fig. 5), and avalanche redistribution (e.g., Fig. 3a) in steep mountain environments. However, such dynamics are not large enough to explain the $33 \mathrm{~m}$ difference in Mt. Chamberlin.

Perhaps not coincidentally, of all of five peaks Mt. Chamberlin is covered by the largest glacier and also shows signs of the largest changes to its peak. In recent years, many glaciated peaks in Alaska have experienced massive rock/ice avalanching (Molnia and Angeli, 2014), and the destabilizing effect of climate warming on mountain peaks has been noted worldwide (Gruber and Haeberli, 2007; Huggel, 2009; Huggel et al., 2012; Enkelmann et al., 2015). For example, Mt. Cook in New Zealand lost more than $10 \mathrm{~m}$ of its peak due to a rock avalanche, and the subsequent destabilization has caused another $20 \mathrm{~m}$ rock and ice loss (Vivero et al., 2012; http://blogs.agu.org/landslideblog/2014/01/16/ aoraki-mount-cook/). Thus if Mt. Chamberlin was indeed over $30 \mathrm{~m}$ higher when the USGS maps were made, likely the change occurred abruptly rather than through gradual melting. The northwest face of Mt. Chamberlin was once covered by a glacier tens of meters thick that likely avalanched catastrophically, as can be deduced by the ice that still remains there through various visualizations (Fig. 6a). The 

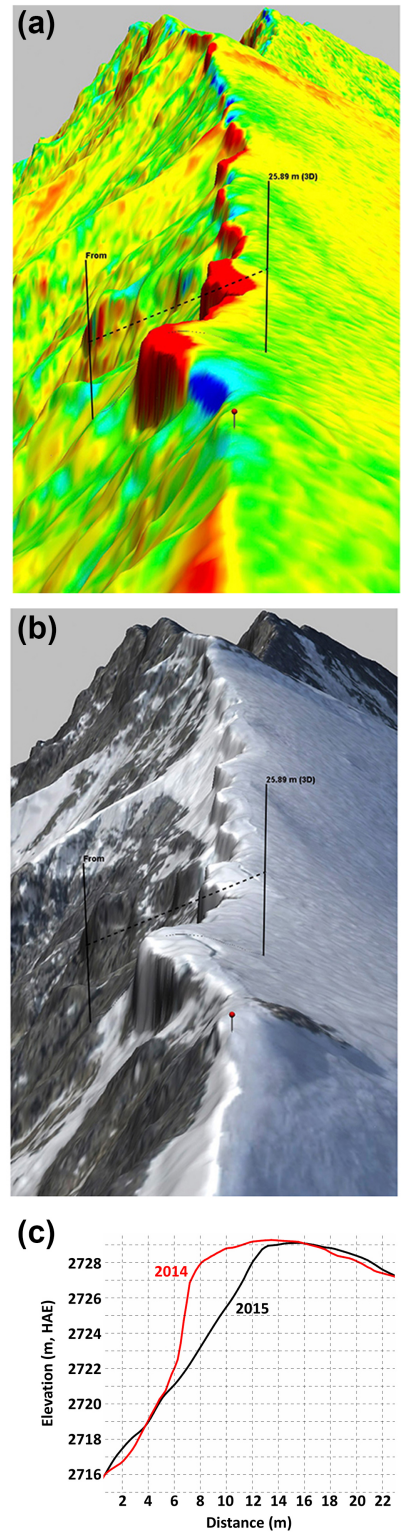

Figure 5. Temporal dynamics of cornices near the peak of Mt. Isto (red push pin). Shown here are 3-D oblique visualizations of fodar from (a) 6 July 2015 and (b) a difference image between 6 July 2015 and 22 April 2014. The consistency of the greens and yellows on either side of the ridge in (b) indicates that there are no spatial misalignments of the two data sets and clearly reveals the differences in cornice size between acquisition dates. The profile comparison (c) confirms visual inspection of the ridge line - a cornice about $5 \mathrm{~m}$ wide and $10 \mathrm{~m}$ high formed, perhaps during a single storm. With these tools we can clearly measure subtle topographic changes in steep mountain environments that would otherwise be impossible to detect or measure, and comparisons like these show change down to the centimeter scale. Dynamics can also be addressed, as the crevassing behind these new cornices (a) indicates the existing ones are ready to spall and the blue colors (b) indicate that many already have. (a)

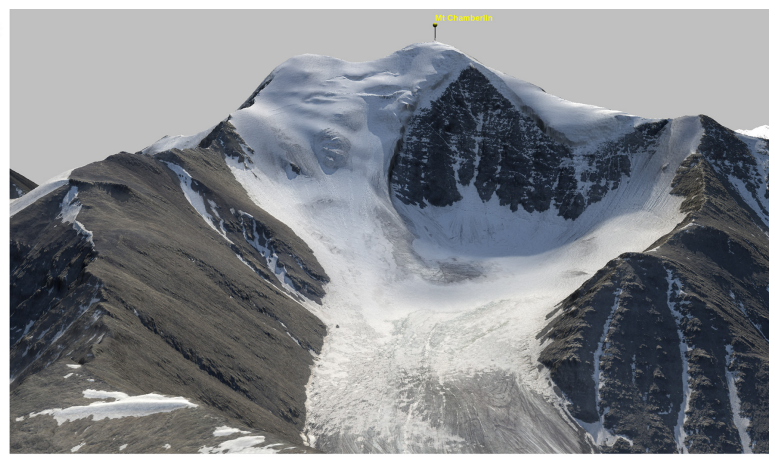

(b)

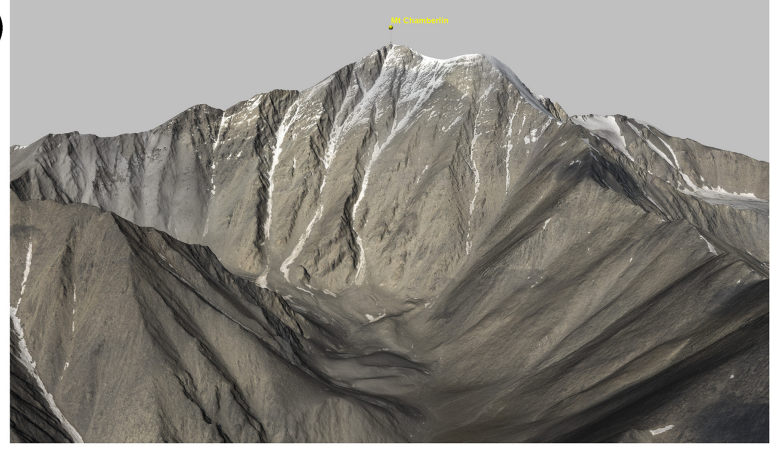

(c)

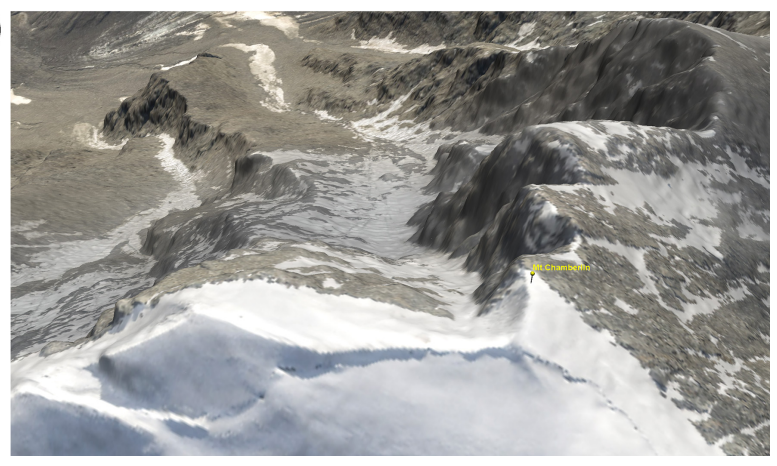

Figure 6. Evidence for recent ice and rock loss from Mt. Chamberlin. (a) The northwest face shows massive, catastrophic loss of ice. (b) The southeast face is now completely free of ice, and rock debris piles have accumulated at its base. (c) Looking down from the peak to towards the southeast face reveals a curious notch in its shape, suggesting rock and ice avalanches may have occurred here in the past. The large map discrepancy along with these clues suggests that Mt. Chamberlin may have been the first or second tallest mountain in the US Arctic at one time.

steep southeast face is now completely free of ice, and at its base there are also large accumulations of rock debris that appears to originate from Mt. Chamberlin rather than the valley glacier at its base (Fig. 6b). The rock near and under these corniced peaks is also prime for frost shattering and rock avalanches, with liquid water from the surface now able to percolate into the bed where temperatures are still below freezing and likely near the optimum -5 to $-15^{\circ} \mathrm{C}$ to cause failures (Walder and Hallet, 1985), and our images show that minor rockfalls are common here. Overall, the ev- 
idence of massive avalanching on the northwest face combined with the notched shape of the peak with $\sim 75^{\circ}$ slopes heading into debris fields at the base of the southeast face (Fig. 6c) lend strong credibility that either rock or ice or both have been lost here. Whether a $33 \mathrm{~m}$ loss could have occurred here is beyond the scope of this paper to determine, but a $5 \mathrm{~m}$ loss seems probable at some point in the recent past, which is enough for Mt. Chamberlin to have once claimed second place in elevation, above Mt. Hubley. We were unable to locate the original photos used to create the USGS maps, and unfortunately other photos we found from that time period are inconclusive due to resolution or snow cover, so for the time being this debate is not fully settled.

Will the ranking of these peaks change in the future? As long as current climate trends continue and no massive rock avalanches occur, the order of the top three is not likely to change due to loss of ice or snow on the summits. Mt. Isto would have to lose over $18 \mathrm{~m}$ of ice to lose its crown, but there is no evidence that such a thickness exists there: the ice is only a few meters thick as gaged from the lee side and exposed rock is encroaching from nearly all sides. Mt. Hubley is the only peak that is not covered by a glacier or permanent cornice as it is on an arête (Fig. 7a), though it does accumulate snow in winter. Mt. Chamberlin will continue to lose elevation, perhaps in catastrophic events, and single storm events are unlikely to even temporarily increase it by the $5 \mathrm{~m}$ needed. Our measurements showed that Mt. Michelson and Mt. Okpilak were only $\sim 1.5 \mathrm{~m}$ apart relative to the WGS84 ellipsoid; a relative geoid anomaly between them of $1.5 \mathrm{~m}$ increased that spread to about $3 \mathrm{~m}$. Both mountains are covered by glaciers that are at least $3 \mathrm{~m}$ thick at their peaks, though where the eventual rock peaks will be is uncertain (Fig. $7 \mathrm{~b}$ and c). Adding to the uncertainty are future improvements to the geoid model here. We tested the experimental $15 \mathrm{~B}$ model and found it gave all peaks $\sim 1.4 \mathrm{~m}$ downward shift compared to the 12B model we used but, given that the $12 \mathrm{~B}$ model indicates a spatial gradient of $1.5 \mathrm{~m}$ between these peaks, future higher-resolution data could yield gradients of that size but with opposite sign, suggesting that this debate is not fully settled. Given that the ranking of these peaks is determined by height differences of 3 to $19 \mathrm{~m}$, a rock avalanche smaller than the size of Mt. Cook's in 1991 could change the order of any of these at any time, though determining whether the local geology is likely to support such large changes will take further research.

We found other sources of error in our data which did not affect our peak measurements, so we did not include them in our uncertainty estimates. Deep shadows on fresh snow on steep headwalls occasionally caused a reduced point density in the fodar point clouds. Here there was essentially no contrast available to find match points. These areas were small and isolated, amounting to less than $5 \%$ of the total areas mapped, as even the track left by a rock rolling downhill can provide enough contrast to constrain elevations there (Fig. 8). Where this point density was simply reduced, a coarser mesh (a)

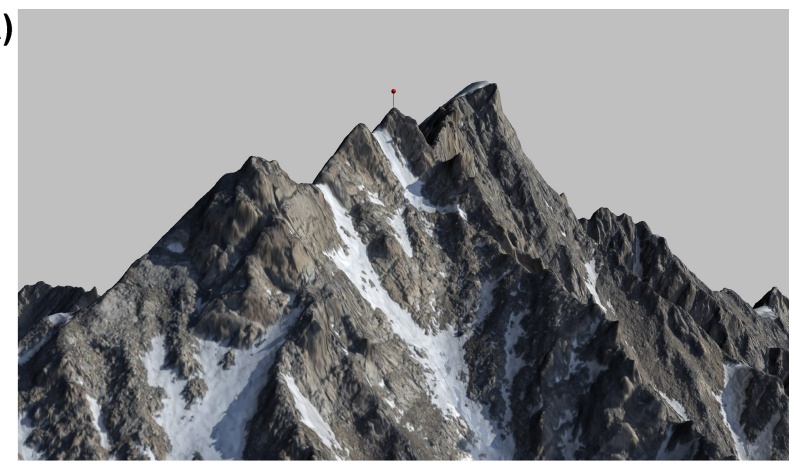

(b)

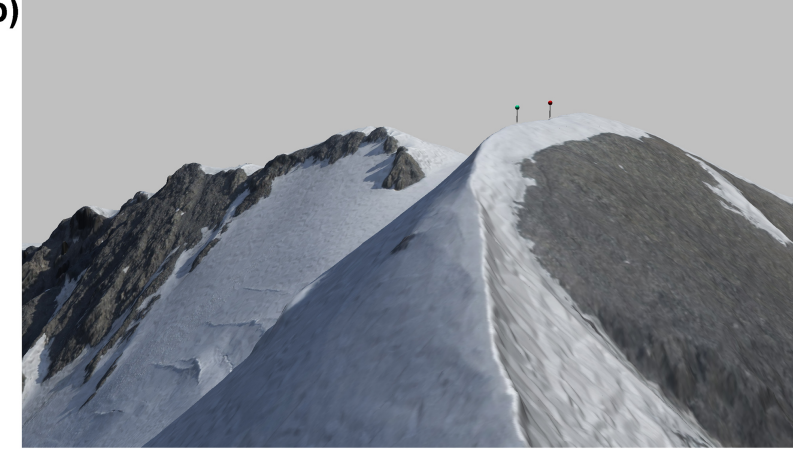

(c)

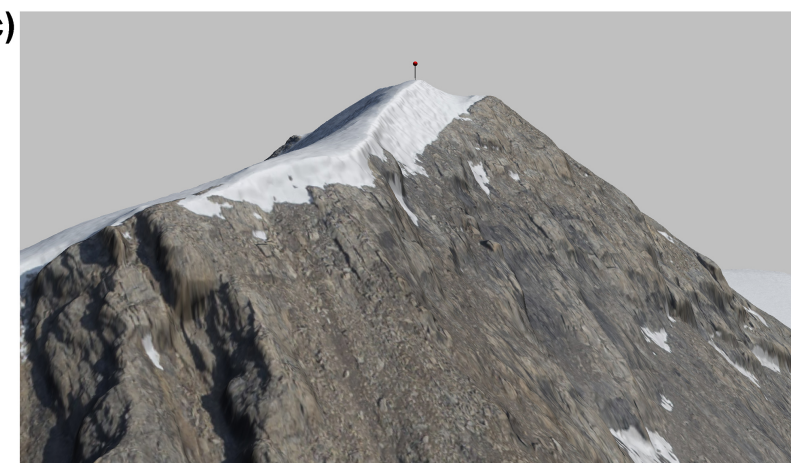

Figure 7. The peak of Mt. Hubley (a) is on a rock arête along a ridge that is too steep and narrow to support large glaciers. Mt. Michelson (b) and Mt. Okpilak (c) are only a few meters apart in height and both are covered by cornices several meters thick. As climate continues to warm, the ranking of these two may yet change. The location of Mt. Okpilak's "peak" moved more than 15 m between 2014 and 2015, as it lies on a nearly flat ridge, but its elevation changed by less than $20 \mathrm{~cm}$.

could be applied and the results interpolated into the DEM; further research is required to determine how well our accuracy and precision specs apply to such areas, but spatial biasing errors will certainly be larger. Where there were no points, gaps could only be filled by pure interpolation or by re-acquiring with a different sun angle. Because our areas could take an hour or more to acquire, moving shadows also caused some noise artifacts at the edges of the shadows moving over low-contrast snow. Occasionally these artifacts were quite large, on the order of $10 \mathrm{~m}$, but in all cases it was clearly 
(a)

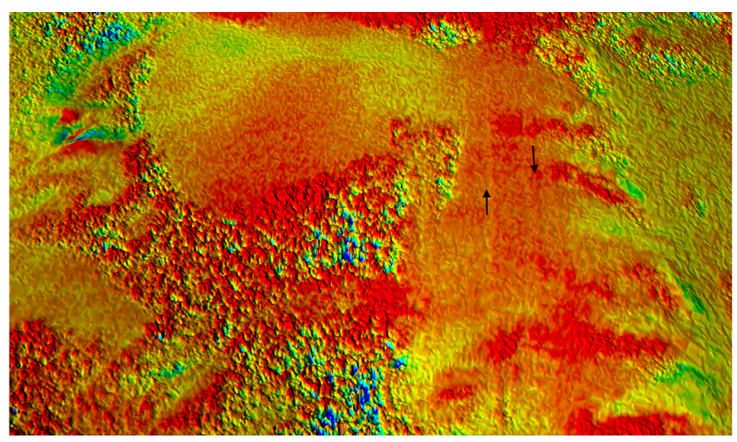

(b)

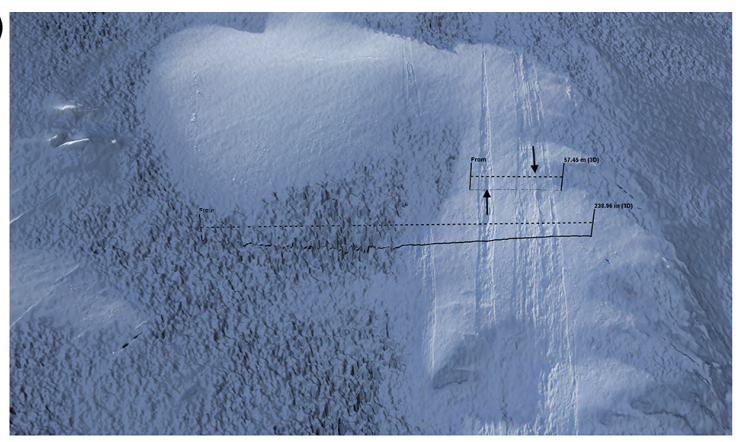

(c)

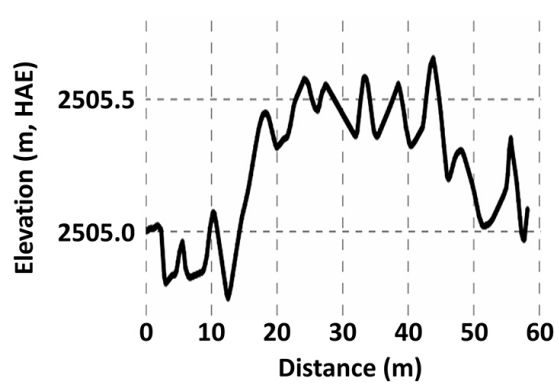

(d)

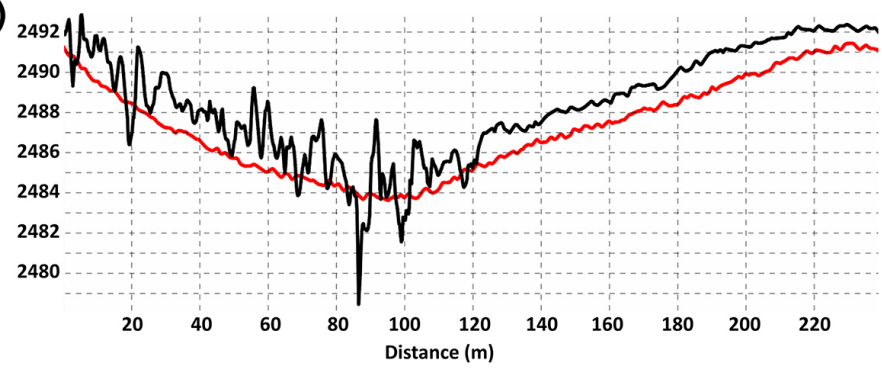

Figure 8. Spatially coherent grooves seen in a 22 April 2014-6 July 2015 difference image on Mt. Isto (a, arrows) are clearly revealed in the July orthoimage (b) to be caused from a small avalanche. As seen in (c), the left arrow points to a $\sim 20 \mathrm{~cm}$ chute and the right arrow points to a $\sim 20 \mathrm{~cm}$ ridge between chutes on this $\sim 40^{\circ}$ slope. Resolving $20 \mathrm{~cm}$ features like this requires centimeter-scale signal detection, despite the noise being on the 5-20 cm level. This snow fell recently and is over a meter thicker than in 2014, located just downhill from the 5-10 m cornices found in Fig. 5. (d) In the deepest shadows of this fresh snow, the noise level increased $\sim \pm 1 \mathrm{~m}$ (up to $10 \mathrm{~m}$, not shown), but these regions were quite small compared to the whole. Note that the 2014 data (red line) show no such noise.

apparent that they were actually artifacts and were easily distinguishable from valid data (e.g., Fig. 8d).

The results of our analyses indicate that our photogrammetric measurements are essentially as accurate as either our GPS or lidar measurements in determining peak elevations, as well as many measuring other features of interest. Table 1 shows that the fodar measurements on all peaks were within $40 \mathrm{~cm}$ of the 2011 lidar. Our repeated fodar measurements at Mt. Isto and Mt. Chamberlin in spring 2014 had differences of only 8 and $19 \mathrm{~cm}$, respectively (Table 1), noting that the cornices on these peaks could have changed on this level or higher due to wind redistribution and melt between measurements. Comparisons of our 22 April maps of Mt. Isto and Mt. Chamberlin to our GPS measurements made 5-11 days later were within only $4 \mathrm{~cm}$, which is better than the accuracy level of the GPS measurements themselves. Note that these fodar measurements involved no corrections for ground control - these are directly georeferenced results utilizing only airborne data. Comparison of two Mt. Isto fodar maps to each other over small areas indicate a repeatability on the order of $\pm 20 \mathrm{~cm}$ (95\% RMSE), including real changes due to snow and ice. This repeatability is superior to the precision we measured using our two best lidar maps over large ice-free areas by more than double. Given that all techniques experience worse precision in steep mountain environments due to spatial biasing caused by GSDs being large compared to terrain variations, fodar outperforms lidar in the sense that fodar GSDs are much smaller than lidar GSDs for the same amount of flight time. That is, fodar's data acquisition rate is over $100 \times$ higher than lidar (e.g., 20-30 megapixels per second compared to $200-300 \mathrm{kHz}$ ) and this results in lower GSDs for the same flying heights and swath widths. In addition to having better precision than lidar, we find photogrammetry much more useful scientifically due to the creation of a perfectly co-registered orthoimage. Using this image, we can, for example, easily distinguish snow from rock (important for snow-free assessments of vertical accuracy or distinguishing landslides from avalanches), determine snow lines on the glacier (important for estimating the density component of volume change), or distinguish vegetation types (important for estimating the compressibility of vegetation due to snow compaction).

The potential value of fodar to earth sciences is difficult to overestimate. The impacts of modern climate change on the Arctic landscape are profound, yet nearly impossible to grasp without a means for affordable time series of landscapescale measurements of topography with centimeter resolution. Though our main usage relates to climate change, there are many other changes occurring globally that can now be measured with improved accuracy and interpretative ability 
for the benefit of society, such as measurement of snow packs in mountain environment for water resource planning, measurement of avalanche danger, or measurement of coastal erosion. Given that we can now not only measure topographic change as accurately from the air than we can from the ground but do so economically over much larger spatial scales, the design, accuracy, and sustainability of our field research programs and operational monitoring efforts can be improved tremendously. In one way or another, landscape change is a driver or response in nearly every physical and ecological study of our planet, and thus we believe that this technology will have a major impact on our understanding of these dynamics.

\section{Conclusions}

Here we have demonstrated a new airborne photogrammetric method that is capable of measuring mountain peaks with an accuracy and precision of better than $\pm 20 \mathrm{~cm}$ at $95 \%$ RMSE. We used this method to measure the heights of the five tallest mountains in the US Arctic, which, in order, are Mt. Isto, Mt. Hubley, Mt. Chamberlin, Mt. Michelson, and an unnamed peak we refer to as Mt. Okpilak. From these results and our substantial prior work in flat and moderate terrain (Gibbs et al., 2015; Kinsman et al., 2015; Nolan et al., 2015; Overbeck et al., 2016), we conclude that this photogrammetric method, fodar, works without reservation to measure ground surface elevation in all terrain types at roughly the same accuracies and precision. The implications of this are manifold - we now have the capability to measure topographic change on the centimeter to decimeter level in flat or mountainous regions using an airborne tool that requires no ground control and is more than 10 times less expensive than the current state of the art.

Author contributions. Matt Nolan led all aspects of technique development, fodar acquisitions, data processing, and data analysis. Kit DesLauriers led all aspects of the climbing expeditions and their GPS measurements.

Acknowledgements. The 2014 climbing expedition and the 22 April 2014 mapping was supported by the National Geographic Society (Expedition Council Grant EC0667-14 to Kit DesLauriers). Development of the methods and other flights were supported by the US Fish and Wildlife Agency and the USGS AK Climate Science Center (CESU 701817K403 and G11AC20549 to Matt Nolan), by The National Science Foundation (PLR-1418274), and by Fairbanks Fodar (http://www.fairbanksfodar.com). The National Science Foundation supported acquisition of the 2008-2011 lidar (ARC-0714045 to Matt Nolan) and McCall Glacier field research (ARC-1023509 to Matt Nolan). We would like thank expedition team members Andy Bardon, Don Carpenter, Hester Jiskoot, Martha Reynolds, and Kasha Rigby for the assistance in the field, as well as Coyote Air and Kristin Nolan for their logistical support.

Edited by: Andreas Kääb

\section{References}

Deems, J. S., Painter, T. H., and Finnegan, D. C.: Lidar measurement of snow depth: a review, J. Glaciol., 59, 467-479, 2013.

d'Oleire-Oltmanns, S., Marzolff, I., Peter, K. D., and Ries, J. B.: Unmanned aerial vehicle (UAV) for monitoring soil erosion in Morocco, Remote Sensing, 4, 3390-3416, 2012.

Enkelmann, E., Koons, P. O., Pavlis, T. L., Hallet, B., Barker, A., Elliott, J., Garver, J. I., Gulick, S. P., Headley, R. M., and Pavlis, G. L.: Cooperation among tectonic and surface processes in the St. Elias Range, Earth's highest coastal mountains, Geophys. Res. Lett., 42, 5838-5846, 2015.

Gao, Y. and Shen, X.: A new method for carrier-phase-based precise point positioning, Navigation, 49, 109-116, 2002.

Geck, J., Hock, R., and Nolan, M.: Geodetic mass balance of glaciers in the Central Brooks Range, Alaska, USA, from 1970 to 2001, Arct. Antarct. Alp. Res., 45, 29-38, 2013.

Gibbs, A., Nolan, M., and Richmond, B.: Evaluating changes to Arctic coastal bluffs using repeat aerial photography and Structure-from-Motion elevation models in: Coastal Sediments 2015, World Scientific, 11-15 May 2015, San Diego, CA, , 2015.

Gruber, S. and Haeberli, W.: Permafrost in steep bedrock slopes and its temperature-related destabilization following climate change, J. Geophys. Res., 112, F02S18, doi:10.1029/2006JF000547, 2007.

Höfle, B. and Rutzinger, M.: Topographic airborne LiDAR in geomorphology: A technological perspective, Z. Geomorphol., 55, 1-29, 2011.

Hugenholtz, C. H., Whitehead, K., Brown, O. W., Barchyn, T. E., Moorman, B. J., LeClair, A., Riddell, K., and Hamilton, T.: Geomorphological mapping with a small unmanned aircraft system (sUAS): Feature detection and accuracy assessment of a photogrammetrically-derived digital terrain model, Geomorphology, 194, 16-24, 2013.

Huggel, C.: Recent extreme slope failures in glacial environments: effects of thermal perturbation, Quaternary Sci. Rev., 28, 11191130, 2009.

Huggel, C., Clague, J. J., and Korup, O.: Is climate change responsible for changing landslide activity in high mountains?, Earth Surf. Proc. Land., 37, 77-91, 2012.

Kinsman, N., Gibbs, A., and Nolan, M.: Evaluation of vector coastline features extracted from 'Structure-from-Motion'15 May 2015, San Diego, CA, 2015.

Koenderink, J. J. and Van Doorn, A. J.: Affine structure from motion, J. Opt. Soc. Am. A, 8, 377-385, 1991.

Lucieer, A., de Jong, S., and Turner, D.: Mapping landslide displacements using Structure from Motion (SfM) and image correlation of multi-temporal UAV photography, Prog. Phys. Geogr., 97-116, doi:10.1177/0309133313515293, 2013.

Molnia, B. and Angeli, K.: Analysis and Anatomy of Several High Latitude, High Elevation Ice-Rock Avalanches, 0307, AGU Fall Meeting Abstracts, December, San Francisco, 2014. 
Nolan, M., Churchwell, R., Adams, J., McClellands, J., Tape, K., Kendall, S., Powell, A., Dunton, K., Payer, D., and Martin, P.: Predicting the impact of glacier loss on fish, birds, floodplains, and estuaries in the Arctic National Wildlife Refuge, 4th Interagency Conference on Research in the Watersheds (ICRW): Observing, Studying, and Managing for Change, Fairbanks, AK, 49-54, 2011.

Nolan, M., Larsen, C., and Sturm, M.: Mapping snow depth from manned aircraft on landscape scales at centimeter resolution using structure-from-motion photogrammetry, The Cryosphere, 9, 1445-1463, doi:10.5194/tc-9-1445-2015, 2015.

Overbeck, J. R., Hendricks, M. D., and Kinsman, N. E. M.: Photogrammetric digital surface models and orthoimagery for 26 coastal communities of western Alaska, in: DGGS Staff, Elevation Datasets of Alaska, Alaska Division of Geological \& Geophysical Surveys Raw Data File 2016-1, Alaska Division of Geological \& Geophysical Surveys, Fairbanks, AK, p. 3, doi:10.14509/29548, 2016.

Rinaudo, F., Chiabrando, F., Lingua, A. M., and Spanò, A. T.: Archaeological site monitoring: UAV photogrammetry can be an answer, The International archives of the photogrammetry, Remote Sens. Spat. Inf. Sci., 39, 583-588, 2012.

Ryan, J. C., Hubbard, A. L., Box, J. E., Todd, J., Christoffersen, P., Carr, J. R., Holt, T. O., and Snooke, N.: UAV photogrammetry and structure from motion to assess calving dynamics at Store Glacier, a large outlet draining the Greenland ice sheet, The Cryosphere, 9, 1-11, doi:10.5194/tc-9-1-2015, 2015.
Snay, R. A. and Soler, T.: Continuously operating reference station (CORS): history, applications, and future enhancements, J. Surv. Eng., 134, 95-104, 2008.

Vivero, S., Sirguey, P., Fitzsimons, S., and Soruco, A.: A New Digital Terrain Model for the Tasman Glacier, New Zealand, using Digital Photogrammetry Techniques, Proceedings of the 8th ICA Mountain Cartography Workshop, Taurewa, New Zealand, 9-14, 2012.

Walder, J. and Hallet, B.: A theoretical model of the fracture of rock during freezing, Geol. Soc. Am. Bull., 96, 336-346, 1985.

Weller, G., Nolan, M., Wendler, G., Benson, C., Echelmeyer, K., and Untersteiner, N.: Fifty years of McCall Glacier research: from the International Geophysical Year, 1957-1958, to the International Polar Year, 2007-2008, Arctic, 60, 101-110, 2007.

Westoby, M., Brasington, J., Glasser, N., Hambrey, M., and Reynolds, J.: 'Structure-from-Motion' photogrammetry: A lowcost, effective tool for geoscience applications, Geomorphology, 179, 300-314, 2012. 